\title{
REVIEW
}

\section{A Scoping Review of Suicide Prevention Training Programs for Pharmacists and Student Pharmacists}

\author{
Amanda N. Stover, PhD, MPH, ${ }^{a}$ Jill E. Lavigne, PhD, MPH, ${ }^{\text {b,c }}$ Delesha M. Carpenter, PhD, MSPH ${ }^{\mathrm{a}, \mathrm{c}}$ \\ ${ }^{a}$ University of North Carolina, Eshelman School of Pharmacy, Chapel Hill, North Carolina \\ ${ }^{\mathrm{b}}$ St John Fisher College, Wegmans School of Pharmacy, Rochester, New York \\ ${ }^{\mathrm{c}}$ Center of Excellence for Suicide Prevention, Department of Veterans Affairs, Canandaigua, New York
}

Corresponding Author: Amanda N. Stover, University of North Carolina, Eshelman School of Pharmacy, 2214 Kerr Hall One University Heights, Asheville, NC 28804. Tel: 828-250-3916. Email: stoveran @email.unc.edu

Submitted October 5, 2021; accepted January 5, 2022; ePublished January 2022

Objective. This scoping review updates a 2018 review of suicide prevention (SP) training programs for community and student pharmacists. Five scholarly databases were searched for articles published between January 2018 and December 2020. Articles were excluded if they: 1) did not describe an educational or training program for pharmacists or student pharmacists; 2) did not explicitly include suicide; 3) focused solely on attitudes; or 4) did not provide sufficient detail to evaluate program content. The quality of each study was examined using a quality assessment tool.

Findings. Seven studies met inclusion criteria. Most trainings (86\%) were delivered live with interactive, or role play scenarios to promote verbal and behavioral skill practice. About half $(57 \%)$ assessed changes in knowledge and fewer programs (29\%) assessed changes in communication. All assessed the ability to identify suicide warning signs and included referral resources. Six studies were assessed for quality; $67 \%$ had a rating of good, and $33 \%$ were rated as fair. Summary. Given the increase in suicide rates nationally, it is likely that pharmacists will encounter a patient in need of suicide prevention services. Since 2018, seven new SP training programs for community and student pharmacists have been reported, which demonstrates growing interest in SP training in the pharmacy profession. When integrated in PharmD curricula, trainings may help prepare the pharmacy workforce for encounters with patients in crisis. The impact of training on self-efficacy and communication skills warrants additional attention. Variation between programs should be evaluated to understand which instructional methods best prepare pharmacy professionals to engage in suicide prevention. Keywords: suicide prevention, training, education, student pharmacist, community pharmacy

\section{INTRODUCTION}

Suicide rates have increased by $35 \%$ in the most recent decade, with a rate of 14.2 per 100,000 people in $2018 .{ }^{1}$ That same year, approximately 10.7 million adults aged 18 or older reported serious thoughts of suicide; of those, 3.3 million made a suicide plan and 1.4 million made a nonfatal suicide attempt. ${ }^{2}$ Despite over a decade of national goals and programs aimed at lowering suicide rates, ${ }^{3}$ several recent reports have documented that suicide rates continue to increase. ${ }^{4,5}$ In part, this may be due to the limited large-scale implementation of multi-faceted public health approaches to suicide prevention. ${ }^{6,7}$ Gatekeeper training has proven to be effective for rapid training and deployment of lay people in K12 education and military settings. ${ }^{8-10}$ Such programs teach community members to identify suicide warning signs and intervene with at-risk individuals when signs are recognized. ${ }^{11,12}$ Yet, gatekeeper training programs have not been systematically integrated into pharmacy education. The United States has more than 68,000 community pharmacies, ${ }^{13}$ many of which are open 24-hours. ${ }^{13,15}$ This allows for pharmacists to be a frequent health care touchpoint for many community members. ${ }^{15,16}$ This makes them well-positioned as gatekeepers for suicide prevention. ${ }^{17}$ Most importantly, community pharmacy staff have reported encountering patients either in crisis or who died by suicide and have expressed their need for suicide prevention skills training. ${ }^{18}$

Yet, despite the accessibility of pharmacy staff, barriers to gatekeeping remain. Common barriers include lack of time,${ }^{19-23}$ privacy ${ }^{21,22}$ discomfort discussing mental illness, ${ }^{22}$ and a more limited view of the scope of community pharmacy practice that precludes suicide prevention. ${ }^{23}$ Despite these barriers, a study of 501 community pharmacy staff in North Carolina found that $21.6 \%$ had been asked about lethal medication doses by patients or encountered patients who requested a lethal dose of medication. ${ }^{19}$ Furthermore, $71.2 \%$ and $34.2 \%$ of student pharmacists reported that they had experienced concerning statements related to their personal lives or while at work, respectively. ${ }^{24}$ In recent years, the number of training programs related to suicide prevention have also increased. 
The objective of this review is to update a 2018 review of the published literature addressing gatekeeper suicide prevention training programs for pharmacists and pharmacy students. ${ }^{25}$ As documentation of the pharmacy workforce's exposure to individuals in crisis continues to grow and the pharmacy profession's role in suicide prevention and mental health has expanded over the past few years, a concomitant increase in suicide training resources for pharmacy professionals would be expected. This information may support community-based pharmacy practices by identifying available suicide prevention strategies as well as gaps in training that can be addressed by future trainings.

\section{METHODS}

Using five scholarly databases (PubMed, International Pharmaceutical Abstracts (IPA), PsycINFO, Scopus, and Google Scholar), we replicated the search strategy from the 2018 review. ${ }^{25}$ Databases were searched for the terms: "pharmacist*" AND ("suicide" OR "suicidal") NOT ("euthanasia" OR "assisted suicide" OR "physician assisted") to identify suicide prevention programs. To identify student pharmacist-focused programs, databases were searched for the following terms: pharmacy student* AND (suicide OR suicidal) NOT (euthanasia OR "assisted suicide" OR "physician assisted"). Inclusion criteria included publication dates between January 2018 and December 2020.

The selection process was conducted in accordance with the Preferred Reporting Items for Systematic Reviews and Meta-Analyses (PRISMA) system (Figure 1). Duplicate articles were removed $(n=176)$, then titles and abstracts were screened for relevance. Articles were excluded if published in a language other than English, or the abstract defined a research population other than community pharmacists or student pharmacists, or broadly discussed community or educational interventions without specifically identifying pharmacy professionals $(n=52)$. Of the remaining articles $(n=48), 41$ were excluded because they: 1$)$ focused solely on depression or mental health screening; 2 ) focused solely on attitudes towards suicide or mental health; and/or 3) did not provide sufficient detail about the training program to evaluate if inclusion criteria were met.

Since some suicide prevention resources for pharmacists may have been developed but not published in the academic literature, we followed the same search strategy as the 2018 review and conducted a Google search (November 2020) with the following key words: 1) "suicide," "training program," and "pharmacist" and 2) "suicide," "training program," and "student pharmacist." The results were limited to the first 100 articles and no new results were identified since the previous review.

During the full text review of resources that met inclusion criteria, the following data were extracted: 1) name of the training program; 2) format of training program (eg, in person, online); 3) length of training; 4) target of training (eg, student pharmacists, pharmacists); 5) learning methods (eg, didactic presentation, role-play); and 6) outcomes assessed (eg, confidence, knowledge). The topics covered were further coded into the following categories: background information, warning signs of suicide, communication with patients, referral resources, medication counseling for suicide prevention, and role play/interactive component.

The quality of each study was examined using the National Heart, Lung, and Blood Institute (NHLBI) quality assessment tool. ${ }^{26}$ This tool was chosen because it evaluates quality based on study design. The tool employs separate checklists tailored for observational cohort and cross-sectional studies, case-control studies, and pre-post studies. The only study type that cannot be evaluated with this tool is qualitative. All checklists are designed to address internal validity (ie, risk of bias) in an equivalent manner. Each checklist item is rated as "yes," "no," "not applicable (NA)," "cannot determine (CD)," or "not reported (NR)." These items form an overall quality rating for each study as "good," "fair," or "poor."

\section{RESULTS}

The search strategy resulted in 176 non-duplicate articles. After application of the inclusion and exclusion criteria, a total of seven articles were included in the final scoping review (Figure 1). All seven articles described live, inperson training programs for pharmacists or student pharmacists (Table 1). Five training programs were for student pharmacists, all of which reported program length, with training time ranging from 50 minutes to 3.5 hours. Time was not reported for the remaining two programs delivered in community pharmacy settings (Table 1).

Of the five programs implemented in pharmacy school curricula, three were in U.S. Doctor of Pharmacy (PharmD) curricula $(60 \%)^{27-29}$ and two were in Bachelor of Pharmacy curricula in Australia (40\%). ${ }^{30,31}$ The remaining two training programs were implemented among community pharmacy staff together with members of the community. One targeted community pharmacists, pharmacy assistants (ie, those who dispense under the supervision of a pharmacist), and members of four local farming communities in Queensland, Australia. ${ }^{32}$ The second targeted lay people, pharmacists, general practitioners, and patients, including survivors of suicide attempt in Germany, Hungary, Portugal, and Ireland ${ }^{33}$ (Table 1). Two of the five student pharmacist suicide prevention gatekeeper programs were embedded in Mental Health First Aid (MHFA) training programs (40\%), but the content and assessments were different. In one study, all students 
completed MHFA training and then a subset of 36 students were randomized to either receive a depression vignette or a suicide vignette. After training, students completed an 8-item self-evaluation on how confidently they could handle a mental health crisis or ask about suicide, depending on their assigned vignette. ${ }^{29}$ In the other study by El-Den and colleagues (2018), MHFA was embedded into the school of pharmacy curriculum and students were randomly assigned to one of three suicide crisis scenarios, each with an in-person simulated patient who had lived experience of mental illness. ${ }^{30}$ Analysis of qualitative interview data identified five themes: benefits to students and simulated patients, value of lived experience, challenges of suicide assessment, confidence in communication, and value in immediate debriefing. Overall, this study found that simulated patient involvement provided a means to practice skills more authentically, mimicking a realistic environment safely, and benefited skill development for students. ${ }^{30}$

The remaining two training programs were implemented among community pharmacy staff together with lay people. Of these, one trained community pharmacists, pharmacy assistants, and members of four local farming communities in Queensland, Australia. ${ }^{31}$ The other targeted lay people as well as pharmacists, general practitioners, and patients, including survivors of suicide attempt in Germany, Hungary, Portugal, and Ireland ${ }^{32}$ (Table 1). One of these two community programs also used MHFA training. ${ }^{31}$ The aims of this training were to explore the potential changes in knowledge, skills, and attitudes of participants. Additionally, this study examined the effect of MHFA training on community members' understanding of the role of pharmacists in supporting individuals with mental illness. ${ }^{31}$

Five topics were taught across all seven training programs: warning signs of suicide, how to communicate with patients who exhibit warning signs, medication counseling and suicide, and referral resources (Table 2). Additionally, six programs $(86 \%)$ incorporated an interactive training component (e.g, role play) to promote verbal or behavioral skills development. Of the six, four included live in person role-play activities $(67 \%) .{ }^{27,29-31}$ The most common skills practiced in three of the four role-play activities was to ask the patient specifically about suicide (75\%). Other skills included identifying warning signs ${ }^{27}$ or assessing for crisis. ${ }^{30}$ One study focused mainly on medication management and how to handle a medication-related ethical dilemma in the context of suicide risk. ${ }^{31}$ Two of the six studies provided written case scenarios in which participants gave written feedback based on a hypothetical patient with suicidal warning signs $(33 \%){ }^{28,32}$

All five trainings for student pharmacists contained a role play or interactive component. Three $(60 \%)$ contained background information and statistics on suicide ${ }^{27-29}$ and two addressed medication counseling (40\%) one addressed risk of medication use in a suicide attempt ${ }^{28}$ and the other provided a scenario of a medication related ethical dilemma and review of medication history. ${ }^{31}$ The second incorporated additional reference materials such as a suicide prevention information card and counseling on antidepressant medications through a course management website as an additional resource..$^{29}$ One student-focused program took the additional step of including resources for participants to seek counseling after discussing emotionally intense topics and a list of available resources for personal use for emotional recovery. ${ }^{27}$ Although both community training programs addressed background information and statistics about suicide and referral resources for individuals at risk of suicide, neither addressed medication counseling. One program addressed how to communicate about and ask about suicide and included an interactive case scenario with brief hypothetical response options. ${ }^{32}$

Three of the seven programs conducted pre- and post-training assessments (43\%). The most common outcomes measured included changes in knowledge (57\%) and perceived relevancy of training to pharmacy/pharmacy staff $(57 \%)$. Fewer than half of all programs reported changes in confidence to interact with suicidal patients (43\%) or changes in ability to recognize warning signs or to intervene to prevent suicide (43\%). Changes in communication skills (ie, asking about suicide or communicating about the topic of suicide) were assessed by $29 \%$ of trainings Other outcomes included awareness of suicide in the broader community (14\%) and benefits of participating in mental health or suicide gatekeeper training programs $(14 \%)$.

Six studies (86\%) used quantitative methods that could be evaluated for quality using the NHLBI quality assessment tool. The seventh study employed a qualitative design. ${ }^{33}$ Of the quantitative studies, four (67\%) had an overall rating of good, and two (33\%) were rated as fair. Studies rated as fair provided minimal details about study methods. All six rated studies relied on self-report measures, making reporting bias the biggest research limitation. One study justified their sample size using statistical methods, while the rest relied on convenience sampling ${ }^{33}$ (Table 3). Sample size could impact the size of the effect seen from pre- to post-training for the three studies that used pre-test/post-test designs.

\section{DISCUSSION}

Given the scope of suicide as a public health problem and the diversity of pharmacy programs and resources, there is a need to evaluate a variety of approaches for educating students and engaging community pharmacists in suicide prevention. ${ }^{26}$ In the original review published in 2018, a total of 16 training programs were identified, four or which targeted student pharmacists. Since the previous review, five suicide prevention training interventions targeting student 
pharmacists and two training programs delivered to the community, including some pharmacists, were published by 2020 . All five trainings for student pharmacists were uniquely different from general population gatekeeper programs in their inclusion of an interactive training component although a minority included medication counseling.

In the aforementioned 2018 review ${ }^{25}$ the authors recommended that suicide prevention training for pharmacy professionals address the following areas: 1) identifying warning signs for suicide; 2) communicating with individuals to assess risk of suicide; 3) referring individuals to appropriate resources; and 4) counseling about which medications may increase risk of suicidal ideation. However, only two of the five trainings for student pharmacists included the medication counseling ${ }^{28,31}$ and the role of medication in suicidal ideation and behavior. Notably, the lack of any medication-specific information such as the medications labelled for risk of suicidal ideation or behavior despite more than 143 agents carrying this label should be included in future training. ${ }^{14}$

Six of the seven programs included an interactive training component. This gave trainees an opportunity to practice their learned skills and receive feedback. The opportunity to practice and receive feedback may be especially important for pharmacy professionals whose training in gatekeeping may be limited to one training and who may have to use gatekeeping skills in practice-based pharmacy. Interactive cases like those used in some trainings have been shown to be effective at supporting student pharmacists in building empathy ${ }^{34}$ and developing counseling skills. ${ }^{35}$ Furthermore, simulation-based exercises, such as the role-play and standardized patient scenario used in some trainings, can improve student pharmacists' communication skills ${ }^{36}$ and ability to effectively convey their knowledge. ${ }^{37}$

Five of the seven trainings reported since the last review were rated of "good" quality; however, they could be improved by incorporating validated assessment measures and clearly defined objective outcomes that can be observed and rated by blinded coders. Additionally, most of the studies in this review used self-reported data that were gathered shortly post-training, which could be impacted by social desirability bias. The two studies that were rated as fair were missing crucial design details. Future studies should report sufficient information about how suicide prevention is incorporated into programming, including time allotted to suicide prevention education, types of resources provided for patient referral, and structure of overall educational intervention (eg, learning methods, topics covered) and assessments (eg, rater qualifications, rubrics, grade and weighting for course credit, anonymity of student feedback, etc.).

Five of the seven articles published since the previous review in 2018 described suicide prevention training with student pharmacists. In the 2018 review, only four programs were delivered to student pharmacists. This increase in student pharmacist-focused programs could, in part, be due to greater professional interest in both how pharmacists engage with patients with mental health disorders and integrating suicide prevention training into pharmacy school curricula to address suicide as a growing public health need. ${ }^{26}$ Educating students on suicide prevention incorporates the appropriate communication skills into pharmacy training before student pharmacists begin practice. By providing activities such as interactive role-play with feedback or video scenarios, learners can model appropriate language for suicide prevention gatekeeping with an individual displaying suicide warning signs in the real world.

The increasing publication of suicide prevention training efforts in pharmacy schools in a matter of a few short years is encouraging, particularly given the considerable demands already placed on curricula and learners when curricular expansion is not accompanied by reductions in other content areas. Integration of extensive stand-alone suicide prevention units in pharmacy school curricula may be impractical; however micro trainings (eg, two to four 15-minute modules), may be sufficient to support gatekeeping, by which pharmacy students recognize patients presenting with warning signs, engage them in conversation and expedite referrals. This gatekeeping training could be readily incorporated into required courses in population health/public health, communication, and pharmacotherapy units about disease states that carry an increased risk of suicide, such as serious mental illnesses, substance misuse, pain or social determinants of health. Notably, pharmacists have been asked to support suicide prevention in settings accredited by the Joint Commission. ${ }^{38}$ Integration of suicide prevention, and specifically brief trainings to support gatekeeping, is likely to support not only our patients but also our students whose increasing utilization of mental health services increases the likelihood that pharmacy students will encounter a classmate, friend, or patient in need of mental health services. ${ }^{39}$

This review has limitations. One limitation of this review is that all articles were reviewed and compiled by one researcher, which may introduce bias. This was addressed systematically by conducting a quality review using a validated tool to assess each article. To reduce the risk of overlap with the previously conducted scoping review, the current review only assessed literature published within the past three years. It is possible that additional programs have been implemented for community pharmacists and student pharmacists that have not been published or reported online. We attempted to capture programs that were not published in peer-reviewed literature by conducting a Google search. However, we could have still missed newly developed suicide prevention programs. 


\section{CONCLUSION}

As pharmacists continue to interact with patients exhibiting warning signs, and the Joint Commission and others set standards for suicide prevention in a wide range of health care settings, demand for suicide prevention skills is likely to increase among student pharmacists and their employers. As the number and variety of trainings continues to expand, future studies should examine the effectiveness of training on pharmacist communication, referral behavior and effectiveness, and patient satisfaction. While a growing body of literature is documenting the effects of suicide prevention training on pharmacists' attitudes, perceptions, and confidence, little is known about pharmacist behavior and ability to engage in suicide prevention in practice. Future studies should investigate the optimal timing for suicide prevention training (ie, year in pharmacy school) and conduct follow-up assessments to address whether training has been used in practice. Additionally, variation between programs, including the frequency and type of content delivered, should be evaluated to better understand what learning methods best prepare pharmacy professionals to engage in suicide prevention gatekeeping behaviors. Further research is needed to define the long-term effects of knowledge and skills acquired during suicide prevention training within the pharmacy profession.

\section{REFERENCES}

1. Hedegaard H, Curtin SC, Warner M. Increase in suicide mortality in the United States, 1999-2018. NCHS Data Brief, no 362. Hyattsville, MD: National Center for Health Statistics. 2020. Accessed January 1, 2022.https://www.cdc.gov/nchs/data/databriefs/db362-h.pdf.

2. Substance Abuse and Mental Health Services Administration. (2019). Key substance use and mental health indicators in the United States: Results from the 2018 National Survey on Drug Use and Health (HHS Publication No. PEP19-5068, NSDUH Series H-54). Rockville, MD: Center for Behavioral Health Statistics and Quality, Substance Abuse and Mental Health Services Administration. https://www.samhsa.gov/data/ Accessed January 1, 2022.

3. U.S. Department of Health and Human Services. Healthy People 2020. Mental health and mental disorders objectives. 2010. https://www.healthypeople.gov/2020/topicsobjectives/topic/mental-health-and-mentaldisorders/objectives. Accessed January 1, 2022.

4. Hedegaard H, Curtin SC, Warner M. Suicide rates in the United States continue to increase. NCHS Data Brief, no 309. Hyattsville, MD: National Center for Health Statistics. Accessed January 1, 2022. https://www.cdc.gov/nchs/data/databriefs/db309.pdf

5. Stone DM, Simon TR, Fowler KA, Kegler SR, Yuan K, Holland KM, et al. Vital Signs: Trends in state suicide rates-United States, 1999-2016 and circumstances contributing to suicide-27 states, 2015. MMWR Morb Mortal Wkly Rep 67(22):617-24. 2018. Accessed January 1, 2022. https://www.cdc.gov/mmwr/volumes/67/wr/pdfs/mm6722a1-H.pdf.

6. Wilcox HC, Wyman PA. Suicide prevention strategies for improving population health. Child Adolesc Psychiatr Clin N Am. 2016;25(2):219-233.

7. Claassen C. National Action Alliance for Suicide Prevention Research Prioritization Task Force. The agenda development process of the United States' National Action Alliance for Suicide Prevention Research Prioritization Task Force. Crisis. 2013; 34(3):147-155.

8. Cross W, Matthieu MM, Lezine D, \& Knox, KL. Does a brief suicide prevention gatekeeper training program enhance observed skills? Crisis. 2010; 31(3): 149-59.

9. Lavigne JE, King DA, Lu NJ, Knox KL, \& Kemp, JE. Pharmacist and pharmacy staff knowledge, attitudes and motivation to refer patients for suicide risk assessment: lessons from Operation SAVE. In Ed. Lavigne JE. (2012) Frontiers in Suicide Prevention and Treatment. Nova Science Publishers.

10. Wyman PA, Brown CH, Inman J, Cross W, Schmeelk-Cone K, Guo J, Pena JB. Randomized trial of a gatekeeper program for suicide prevention: 1-year impact on secondary school staff. Journal of consulting and clinical psychology. 2008; 76(1): 104.

11. Burnette, C., Ramchand, R., \& Ayer, L. Gatekeeper training for suicide prevention: A theoretical model and review of the empirical literature. Rand health quarterly. 2015; 5(1): 16.

12. Knox KL, Pflanz S, Talcott GW, et al. The US Air Force suicide prevention program: implications for public health policy. Am J Public Health. 2010;100(12):2457-2463. doi:10.2105/AJPH.2009.159871

13. Qato DM, Zenk S, Wilder J, Harrington R, Gaskin D, Alexander GC. The availability of pharmacies in the United States: 2007-2015. PLoS One. 2017;12(8): e0183172.

14. Lavigne JE. Suicidal ideation and behavior as adverse events of prescribed medications: an update for pharmacists. J Am Pharm Assoc. 2016; 56(2): 203-206. 
15. Tubbs AS, Perlis ML, Basner M, Chakravorty S, Khader W, Fernandez F, Grandner MA. Relationship of nocturnal wakefulness to suicide risk across months and methods of suicide. J Clin Psychiatry. 2020; 81(2).

16. Drug Topics: Voice of the Pharmacist. NACDS 2009e2010 chain pharmacy industry profile. Available at: http://drugtopics.modernmedicine.com/drug topics/news/modernmedicine/modern-medicine-news/nacds-20102011-chain-pharmacy-industry-profile. Accessed January 1, 2022.

17. Berenbrok LA, Gabriel N, Coley KC et al. Evaluation of frequency of encounters with primary care physicians vs visits to community pharmacies among Medicare beneficiaries. JAMA Network Open. 2020; 3(7): e209132-e32.

18. Kassir H, Eaton H, Ferguson M, Procter NG. Role of the pharmacist in suicide prevention: primely positioned to intervene. J Pharm Pract Res. 2019; 49(6): 567-569.

19. Carpenter DM, Lavigne JE, Colmenares EW, Falbo K, \& Mosley SL. Community pharmacy staff interactions with patients who have risk factors or warning signs of suicide. Research in social and administrative pharmacy. 2020; 16(3): 349-359.

20. Leong C, Sareen J, Enns MW, Bolton J, Alessi-Severini S. Community pharmacy practice barriers in preventing drug misuse, divergence, and overdose: a focus group study. Healthc Q. 2015; 18(3):28e33.

21. Murphy AL, Martin-Misener R, Kutcher SP, O'Reilly CL, Chen TF, Gardner DM. From personal crisis care to convenience shopping: an interpretive description of the experiences of people with mental illness and addictions in community pharmacies. BMC Health Serv Res.2016; 16(1):569.

22. Phokeo V, Sproule B, Raman-Wilms L. Community pharmacists' attitudes toward and professional interactions with users of psychiatric medication. Psychiatr Serv. 2004; 55(12):1434e1436.

23. Laliberté MC, Perreault S, Damestoy N, Lalonde, L. Ideal and actual involvement of community pharmacists in health promotion and prevention: a cross-sectional study in Quebec, Canada. BMC public health. 2021;12(1), 111.

24. Witry M, Clayden A. Student pharmacist personal and work experiences with people displaying warning signs of suicidal ideation. Mental Health Clinician. 2020; 10(4), 244-249.

25. Carpenter DM, Lavigne JE, Roberts CA, Zacher J, \& Colmenares EW. A review of suicide prevention programs and training policies for pharmacists. J Amer Pharm Assoc. 2018; 58(5): 522-529.

26. National Institutes of Health (2014). Quality Assessment Tool for Observational Cohort and Cross-Sectional Studies. Available online at: https://www.nhlbi.nih.gov/health-pro/guidelines/in-develop/cardiovascular-riskreduction/tools/cohort. Accessed January 1, 2022.

27. Willson MN, Robinson JD, McKeirnan KC, Akers JM, \& Buchman CR. Training Student Pharmacists in Suicide Awareness and Prevention. Amer J Pharm Educ. 2021; 84(8).

28. Witry MJ, Neblett K, Hutchens S, Catney C. When a patient talks about suicide: Adding a social worker led session on the pharmacist's role in suicide prevention to the PharmD curriculum. Curr Pharm Teach Learn. 2019; 11(6), 585-591.

29. Witry M, Kauer J, Fravel M, Reist J,Viyyuri, B. Evaluation of a question persuade refer (QPR) training for student pharmacists. Mental Health \& Prevention. 2020; 18: 200180.

30. El-Den S, Chen TF, Moles RJ, \& O'Reilly C. Assessing mental health first aid skills using simulated patients. Amer J Pharm Educ. 2018; 82(2).

31. O’Reilly CL, Moles RJ, Boukouvalas E, \& El-Den, S. Assessing students' mental health crisis skills via consumers with lived experience: a qualitative evaluation. The Journal of Mental Health Training, Education and Practice. 2019; 14(5): 361-371

32. Shams S, \& Hattingh HL. Evaluation of mental health training for community pharmacy staff members and consumers. J of Phar Pract Res, 2020; 50(2), 160-165.

33. Hegerl U, Maxwell M, Harris F, Koburger N, Mergl R, Székely A, OSPI-Europe Consortium. Prevention of suicidal behaviour: Results of a controlled community-based intervention study in four European countries. PloS one. 2019; 14(11): $\mathrm{e} 0224602$.

34. Chua, JYX, Ang E, Lau STL, \& Shorey S. Effectiveness of simulation-based interventions at improving empathy among healthcare students: A systematic review and meta-analysis. Nurse Educ Today. 2021; 105000.

35. Wolters M, van Paassen JG, Minjon L, Hempenius M, Blokzijl MR, Blom L. Design of a Pharmacy Curriculum on Patient Centered Communication Skills. Pharmacy. 2021; 9(1):22.

36. Forbes R, Clasper B, Ilango A, Kan H, Peng J, \& Mandrusiak, A. Effectiveness of patient education training on health professional student performance: a systematic review. Patient Educ Couns. 2021; 104(10): 2453-2466.

37. Alshammari, E. Simulated role-playing in pharmacy. International Journal of Pharmaceutical Quality Assurance. 2020; 11(01): 173-178. 
38. Traynor, K. Pharmacists can help implement suicide prevention goal. 2019. American Society of Health-System Pharmacists. Available online at: https://www.ashp.org/News/2019/07/29/Pharmacists-Can-Help-ImplementSuicide-Prevention-Goal?loginreturnUrl=SSOCheckOnly. Accessed January 1, 2022.

39. Lipson SK, Lattie EG, Eisenberg D. Increased rates of mental health service utilization by US college students: 10-year population-level trends (2007-2017). Psychiatr Serv. 2019; 70(1): 60-63. 
Figure 1. PRISMA flow diagram for inclusion of studies in scoping review

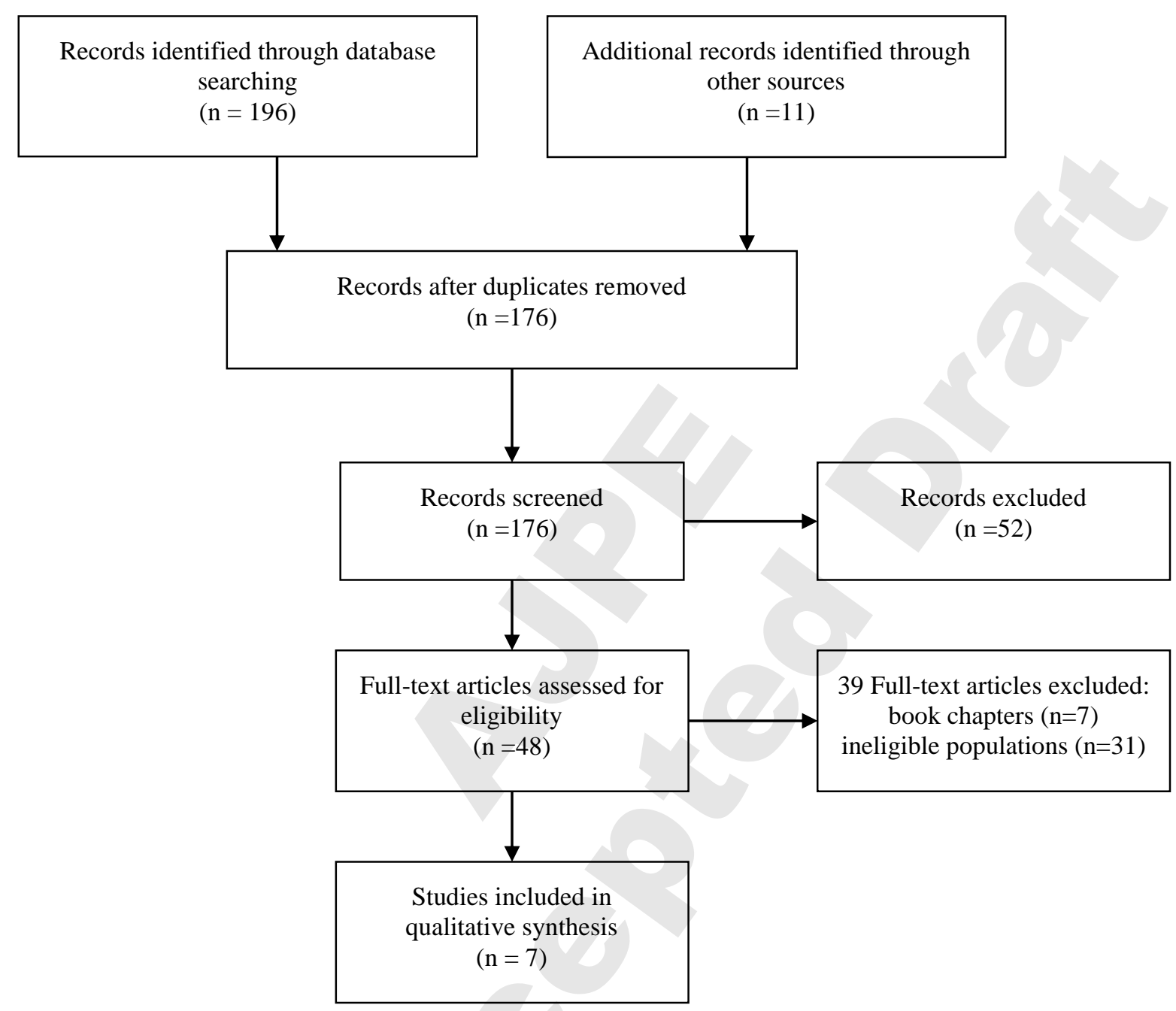




\begin{tabular}{|c|c|c|c|c|c|c|c|}
\hline $\begin{array}{ll} & \text { Author } \\
\text { 总 } & \\
\stackrel{\infty}{=} & \end{array}$ & Year & $\begin{array}{l}\text { Name of Training } \\
\text { Program }\end{array}$ & Format & Length & Target & Learning Methods & Outcomes Assessed \\
\hline 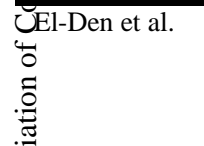 & 2018 & $\begin{array}{l}\text { Mental Health First Aid } \\
\text { (MHFA) }\end{array}$ & In-person & NR & $\begin{array}{l}\text { Student Pharmacists } \\
\end{array}$ & $\begin{array}{l}\text { Two vignettes, one suicide simulated patient } \\
\text { role-play (audio-recorded), post-training self- } \\
\text { assessment post training based on the MHFA } \\
\text { Action Plan }\end{array}$ & $\begin{array}{ll} & \text { Knowledge } \\
- & \text { Confidence } \\
\text { - Skills identifying and preventing } \\
\text { suicide }\end{array}$ \\
\hline 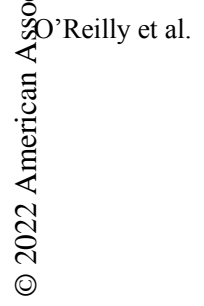 & 2019 & $\begin{array}{l}\text { Mental Health First Aid } \\
\text { (MHFA) }\end{array}$ & In-Person & NR & Student Pharmacists & $\begin{array}{l}\text { MHFA using simulated role-plays enacted } \\
\text { by people with a lived experience of mental } \\
\text { illness. }\end{array}$ & $\begin{array}{ll}\text { Thematic content analysis: } \\
\text { - } & \text { Benefits of participating } \\
\text { - } & \text { Calue of having lived experience } \\
\text { - } & \text { assessmes with suicide } \\
\text { - } & \text { Communication } \\
& \text { Value of immediate feedback \& } \\
& \text { debrief }\end{array}$ \\
\hline 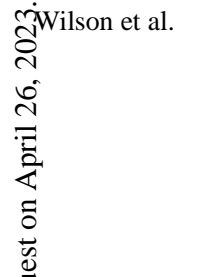 & 2020 & $\begin{array}{l}\text { Suicide Prevention for } \\
\text { Pharmacy Professionals }\end{array}$ & $\begin{array}{l}\text { In-Person; } \\
\text { video content; } \\
\text { pre- and post- } \\
\text { training } \\
\text { assessments }\end{array}$ & $3.5 \mathrm{~h}$ & Student Pharmacists & $\begin{array}{l}\text { Taught as a one-week module. Didactic } \\
\text { portions were in a video-recorded format and } \\
\text { included six 10-20-minute videos to be } \\
\text { completed before laboratory sessions. A live } \\
90 \text {-minute laboratory session was designed } \\
\text { to practice incorporating Safer Homes } \\
\text { messaging and apply LEARN* framework to } \\
\text { role-play scenarios and group discussion. }\end{array}$ & $\begin{array}{ll}\text { - } & \text { Knowledge } \\
\text { - } & \text { Confidence } \\
\text { Skills in identifying suicide } \\
\text { prevention (ie, look for warning } \\
\text { signs of suicide) for patients, } \\
\text { peers, family, and friends after } \\
\text { training }\end{array}$ \\
\hline 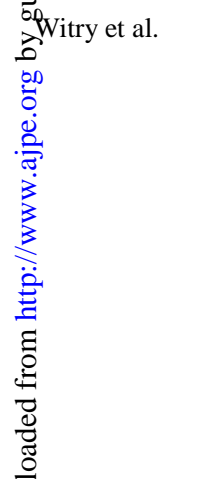 & 2020 & $\begin{array}{l}\text { Evaluation of a Question } \\
\text { Persuade Refer (QPR) } \\
\text { Training for Student } \\
\text { Pharmacists }\end{array}$ & $\begin{array}{l}\text { In-Person; pre- } \\
\text { post session } \\
\text { assessment }\end{array}$ & $1 \mathrm{~h}$ & Student Pharmacists (second year) & $\begin{array}{l}\text { Didactic slide presentation led by a } \\
\text { psychiatric pharmacist and QPR training as } \\
\text { part of a 6-week Neurology-Psychiatry } \\
\text { Integrated Pharmacotherapy course. } \\
\text { Information on suicide statistics, } \\
\text { misconceptions, principles, and introduction } \\
\text { to the SAVE program used by the Veterans } \\
\text { Affairs. A didactic case was provided for } \\
\text { discussion and the facilitator discussed } \\
\text { counseling for antidepressant medications. } \\
\text { Training also included anonymous pre- and } \\
\text { post-surveys which were used to evaluate the } \\
\text { program for changes in confidence and } \\
\text { knowledge. }\end{array}$ & $\begin{array}{ll}- & \text { Knowledge } \\
- & \text { Confidence } \\
& \text { How to improve training }\end{array}$ \\
\hline है & 2019 & $\begin{array}{l}\text { Social Worker-Pharmacist } \\
\text { Collaborative Didactic } \\
\text { Lecture }\end{array}$ & In-Person & 50 minutes & $\begin{array}{l}\text { Student Pharmacists } \\
\text { (first year) }\end{array}$ & $\begin{array}{l}\text { Didactic session covering: } \\
\text { (1) suicide statistics } \\
\text { and public health significance } \\
\text { (2) protective factors, risk factors, and } \\
\text { warning signs of } \\
\text { suicidal ideation } \\
\text { (3) strategies for asking about suicidal } \\
\text { ideation, including practice asking about } \\
\text { Suicide } \\
\text { (4) resources and referrals } \\
\text { (5) brief case scenarios and student questions }\end{array}$ & $\begin{array}{l}\text { - Assessment of novelty of material } \\
\text { - Relevancy of the topic to } \\
\text { pharmacists } \\
\text { - Confidence in student's ability to } \\
\text { ask about suicide } \\
\text { - Confidence to question a patient } \\
\text { about suicide }\end{array}$ \\
\hline
\end{tabular}




\begin{tabular}{|c|c|c|c|c|c|c|c|}
\hline $\begin{array}{ll} & \text { Author } \\
\mathscr{\varpi}_{0} & \\
\triangleq & \\
\end{array}$ & Year & $\begin{array}{l}\text { Name of Training } \\
\text { Program }\end{array}$ & Format & Length & Target & Learning Methods & Outcomes Assessed \\
\hline 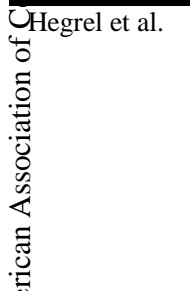 & 2019 & $\begin{array}{c}\text { Optimizing Suicide } \\
\text { Prevention Programmes } \\
\text { and Their Implementation } \\
\text { in Europe } \\
\text { (OSPI-Europe) }\end{array}$ & $\begin{array}{l}\text { In-Person; } \\
\text { Written } \\
\text { Material; } \\
\text { Infrastructure } \\
\text { changes }\end{array}$ & Varied & $\begin{array}{l}\text { General practitioners, "community } \\
\text { facilitators and gatekeepers" (i.e } \\
\text { priests, policemen, pharmacists), } \\
\text { patients, survivor relatives, families }\end{array}$ & $\begin{array}{l}\text { Intervention study with four levels: } \\
1 . \quad \text { training of primary care providers } \\
2 . \quad \text { a public awareness campaigns } \\
3 . \quad \text { training of community facilitators, } \\
4 . \quad \text { support for patients and their relatives. } \\
\text { public awareness events, flyers, posters, } \\
\text { didactic learning courses, media delivered } \\
\text { anti-suicide campaigns }\end{array}$ & $\begin{array}{l}\text { - } \quad \text { Number of suicide acts } \\
\text { Changes in frequency of suicidal } \\
\text { acts at one-year } \\
\text { - Changes in: } \\
\text { • Attitudes } \\
\text { •Knowledge } \\
\text { • Awareness of suicide and } \\
\text { depression }\end{array}$ \\
\hline 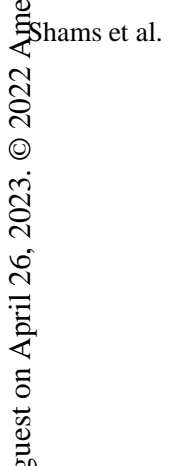 & 2020 & $\begin{array}{l}\text { Mental Health First Aid } \\
\text { (MHFA) } \\
\text { "Commity Farmacy-The } \\
\text { Helping Hand Initiative" }\end{array}$ & $\begin{array}{l}\text { In-Person; } \\
\text { online surveys }\end{array}$ & NR & $\begin{array}{l}\text { Pharmacy staff (pharmacists and } \\
\text { pharmacy technicians), consumers } \\
\text { (members of local farming } \\
\text { communities) }\end{array}$ & $\begin{array}{ll}\text { - } & \text { Attended } 12 \text { hours MHFA training } \\
\text { - PowerPoint slide presentation and } \\
\text { informational sheet (didactic) } \\
\text { - } & \text { Practiced application of skills } \\
\text { Provided pre-training and post-training } \\
\text { feedback }\end{array}$ & $\begin{array}{l}\text { - Changes in knowledge, skills, and } \\
\text { attitudes of pharmacy staff and } \\
\text { community members } \\
\text { Community member } \\
\text { understanding of the role of local } \\
\text { community pharmacies in } \\
\text { supporting people with mental } \\
\text { illness } \\
\text { Changes in pharmacy staff } \\
\text { practices when providing services } \\
\text { and working with the broader } \\
\text { community }\end{array}$ \\
\hline
\end{tabular}


Table 2. Inclusion of Key Topics for Suicide Prevention Training Programs for Pharmacists and Pharmacy Students

\begin{tabular}{|c|c|c|c|c|c|c|c|}
\hline \multicolumn{8}{|c|}{ Student Pharmacist Training Programs } \\
\hline Author & Training Program & $\begin{array}{c}\text { Suicide } \\
\text { Background } \\
\text { Information }\end{array}$ & $\begin{array}{l}\text { Warning Signs } \\
\text { of Suicide }\end{array}$ & $\begin{array}{l}\text { Communication } \\
\text { with Patients }\end{array}$ & $\begin{array}{l}\text { Referral } \\
\text { Resources }\end{array}$ & $\begin{array}{c}\text { Medication } \\
\text { Counseling for Suicide } \\
\text { Prevention }\end{array}$ & Role Play/Interactive \\
\hline $\begin{array}{l}\text { El-Den et al. } \\
(2018)\end{array}$ & Mental Health First Aid (MHFA) & $\mathrm{X}$ & $\checkmark$ & $\checkmark$ & $\checkmark$ & $\mathrm{X}$ & $\checkmark$ \\
\hline $\begin{array}{l}\text { O'Reilly et al. } \\
\text { (2019) }\end{array}$ & Mental Health First Aid (MHFA) & $\mathrm{X}$ & $\checkmark$ & $\checkmark$ & $\checkmark$ & $\checkmark$ & $\checkmark$ \\
\hline $\begin{array}{l}\text { Wilson et al. } \\
(2020)\end{array}$ & $\begin{array}{l}\text { Suicide Prevention for Pharmacy } \\
\text { Professionals }\end{array}$ & $\checkmark$ & $\checkmark$ & $\checkmark$ & $\checkmark$ & $\mathrm{X}$ & $\checkmark$ \\
\hline $\begin{array}{l}\text { Witry et al. } \\
(2020)\end{array}$ & $\begin{array}{l}\text { Question Persuade Refer (QPR) } \\
\text { Suicide Prevention }\end{array}$ & $\checkmark$ & $\checkmark$ & $\checkmark$ & $\checkmark$ & $\checkmark$ & $\checkmark$ \\
\hline $\begin{array}{l}\text { Witry et al. } \\
\text { (2019) }\end{array}$ & $\begin{array}{l}\text { Social Worker-Pharmacist } \\
\text { Collaborative Didactic Lecture }\end{array}$ & $\checkmark$ & $\checkmark$ & $\checkmark$ & $\checkmark$ & $\mathrm{X}$ & $\checkmark$ \\
\hline \multicolumn{8}{|c|}{ Community Pharmacist Training Programs } \\
\hline Author & Training Program & $\begin{array}{l}\text { Background \& } \\
\text { Statistics }\end{array}$ & Signs of Suicide & Communication & $\begin{array}{c}\text { Referral } \\
\text { Resources }\end{array}$ & $\begin{array}{l}\text { Medication } \\
\text { Counseling }\end{array}$ & Role Play/Interactive \\
\hline $\begin{array}{l}\text { Hegrel et al. } \\
(2019)\end{array}$ & $\begin{array}{l}\text { Optimizing Suicide Prevention } \\
\text { Programmes \& Their } \\
\text { Implementation in Europe (OSPI- } \\
\text { Europe) }\end{array}$ & $\checkmark$ & $\checkmark$ & $\mathrm{X}$ & $\checkmark$ & $X$ & $X$ \\
\hline $\begin{array}{l}\text { Shams et al. } \\
(2020)\end{array}$ & $\begin{array}{l}\text { Mental Health First Aid (MHFA) } \\
\text { "Community Farmacy-The } \\
\text { Helping Hand Initiative" }\end{array}$ & $\checkmark$ & $\checkmark$ & $\checkmark$ & $\checkmark$ & $X$ & $\checkmark$ \\
\hline
\end{tabular}


